Fifth International Conference on Sustainable Construction Materials and

Technologies. http://www.claisse.info/Proceedings.htm

\title{
Use of Oil Palm Broom Fibres for Eco-friendly Concrete
}

\author{
Emmanuel Owoichoechi Momoh ${ }^{1}$ Adelaja Israel Osofero ${ }^{2}$ \\ School of Engineering, University of Aberdeen, Kings College, Aberdeen, United Kingdom ${ }^{1,2}$ \\ r01eom18@abdn.ac.uk $k^{1}$ aiosofero@abdn.ac.uk ${ }^{2}$
}

\begin{abstract}
The use of vegetative fibres in reinforcing concrete is currently attracting research attention because it is void of the high carbon footprint and cost associated with use of conventional reinforcements like steel. One of such vegetable fibres is the ribs of the leaflets of the oil palm tree whose only use has been for making brooms. However, these ribs referred to as Oil Palm Broom Fibres (OPBF) have mechanical characteristics similar to steel and can be incorporated in concrete to improve its mechanical properties. With a specific gravity of 0.84 , an average length of $800 \mathrm{~mm}$ and cross-sectional diameter varying between $0.20 \mathrm{~mm}$ (at the tail) and $4.00 \mathrm{~mm}$ (at the head), maximum tensile strength of 900MPa was recorded in the study, hence making the fibres superior to steel in terms of strength-to-weight ratio. Optical microscopy of fibre cross sections reveals randomly dispersed xylem cavities, a densely packed core but lightly packed cortex. This radial and longitudinal density gradient is responsible for the phenomenon whereby towards the cap of the fibres, the fibres are stiffer in bending but reduces in tensile strength. Investigation of mechanical properties of concrete incorporating $O P B F$ as random fibre-reinforcement was carried out. Although the inclusion of $O P B F$ in concrete reduces its compressive strength, the post-yield behaviour shows that energy absorption of the composite is enhanced, making OPBF-concrete a potential material for low-cost seismic construction.
\end{abstract}

Keywords: Construction; Eco-friendly concrete; Natural fibres; OPBF; Oil Palm Broom Fibres; OPBFconcrete; Mechanical properties.

Corresponding author: Emmanuel Owoichoechi Momoh

Email:r01eom18@abdn.ac.uk 


\section{INTRODUCTION}

Current level of atmospheric carbon dioxide stands at 390ppm with the building sector responsible for 50\% of these emissions [1]. The building sector alone consumes $40 \%$ of the total world energy, $25 \%$ of the global water and $40 \%$ of the total resources in the world; and responsible for one-third of the total emission of greenhouse gases. Differently put, there has been an increase in emission of about $39 \%$ from the pre-industrial era thereby representing an average annual growth rate of 3.7\% [2]. According to Claramunt et al. [3], the increasing levels of carbon dioxide in the atmosphere require urgent attention from all stakeholders in the construction industry. In addition to these statistics of available environmental data, the ever-increasing cost associated with provision of infrastructure through conventional (but non-sustainable) processes (like mining iron ore for steel production for reinforced concrete), pose a continual difficulty for governments of developing countries in providing decent housing for her citizens. Hence there exists need for research into development of alternative natural fibre materials which are cheap, readily available, considerably more economical in production and usage and more environmentally friendly [2-10].

Unlike steel, natural fibres are obtained from plants, animals and geological processes. Natural fibres are not only readily available but are considerably more economical to handle during production and usage and are more environmentally friendly. Among the advantages of including natural fibres in concrete are; low-cost, zero-carbon footprint, light-weightiness, toughness, biodegradability, non-toxicity to the ecosystem, thermal insulation, improved acoustic insulation and high recyclability [10-15]. Balasubramanian et al. [16], reports that the use of natural fibres in cement composites gives $10 \%$ reduction in weight, $80 \%$ reduction in energy required for production, and 5\% reduction in cost of component used when compared to a fibre-glass reinforced component. It is also reported that 50 times more energy is required for producing conventional steel reinforcement than is required for equivalent bamboo reinforcement [17]. Construction applications in which natural fibres have been recommended include; cementitious roofing sheets [18], claddings and building insulation [3, 12, 13], self-compacting mortar [11, 19], polymer composites [20-22] and reinforced concrete [23].

One of the huge sources of natural fibres is the oil palm tree. These fibres are usually the by-products of palm oil extraction, oil palm cultivation or the remains of oil palm trees at the end of their useful life. In developing 
countries, the waste fibres are either burnt in the open field, dumped indiscriminately at refuse dumps or used to make fire for cooking, thereby leading to pollution of the environment [24].

\subsection{Oil Palm Fibres}

The earliest record of investigation into reinforcing concrete with oil palm fibres was in the 1980's [16], making the oil palm tree (Elaeis guineensis) one out of the many sources of natural fibres that have attracted research attention. Possible uses of oil palm fibres in construction have been investigated and previous studies have shown possible applications of these fibres [12,15,18,24-32]. Investigations into the engineering properties and possible applications of fibres obtained from different parts of the oil palm tree can also be found [27, 33]. Types of oil palm fibres include; Empty fruit bunch fibres (EFBF), frond fibres (OPFF), trunk fibres (OPTF) and broom fibres (OPBF). However, the potential of OPBF has not been explored except for the study of Momoh and Dahunsi [18], which used fibres obtained from the leaflets of the oil palm tree $(\mathrm{OPBF})$ as reinforcement in laterite-based roof tiles. Fig 1.1 presents an illustration of the broom fibres.

In the rural areas of Nigeria, oil palm leaves are harvested for making sheds and roofs of mud houses and for the extraction of the ribs of the leaflets. The leaflets are first detached from the petioles after which the leaves are peeled off the ribs of the leaflets (see Fig. 1.1). This extraction process is usually done manually with the aid of a machete or knife although automated extraction is now possible [34]. The broom fibres are then tied into broom units only to be sold at local markets. Momoh and Dahunsi [18] studied the suitability of OPBF as reinforcement for laterite-based roof tiles by fabricating the fibres into meshes of varying gauge sizes $(10 \mathrm{~mm}, 20 \mathrm{~mm}, 30 \mathrm{~mm}, 40 \mathrm{~mm}$ and $50 \mathrm{~mm})$, and embedding the OPBF reinforcement meshes in lateritecement matrices of $(300 \times 150 \times 12) \mathrm{mm}$. Up to $130 \%$ improvement in flexural strength of the roof tiles was reported at 28 days of curing of the samples. An optimum mesh size of $10 \mathrm{~mm}$ was recommended as OPBFreinforcement for the roof tiles. Tensile strength in excess of $1000 \mathrm{MPa}$ was reported for the broom fibres. The implication of this is that replacing steel bars with OPBF as main reinforcement for concrete is possible. This will reduce labour cost and improve construction speed due to the light-weightiness of the resulting concrete.

One broom unit which consists of 150-250 broom fibres, each having an average length and cross-sectional diameter of $800 \mathrm{~mm}$ and $1.5 \mathrm{~mm}$ respectively is worth about USD 0.11 in Nigeria. OPBF of USD 0.22 worth 
could adequately reinforce a $(225 \times 300 \times 1200) \mathrm{mm}$ lintel beam thereby reducing reinforcement cost by over $90 \%$. With an approximate density of $0.84 \mathrm{~g} / \mathrm{cm}^{3}$, OPBF is only $20 \%$ of the density of reinforcing steel, thus making OPBF superior in terms of its strength-to-weight ratio. These reasons have hence, motivated this research.

This study therefore investigates some physico-mechanical properties of OPBF and mechanical properties of concrete incorporating short discrete OPBF here-in referred to as OPBF-concrete.

\section{EXPERIMENTAL PROGRAMME}

\subsection{Oil Palm Broom Fibres (OPBF)}

The experimental campaign started with investigating some physical and mechanical properties of OPBF. The fibres were then incorporated in concrete at various replacement levels of total aggregate volume. The following section discusses the experimental studies carried out.

\subsubsection{Determination of Cross-sectional Areas}

Oil palm broom fibres (OPBF) were obtained from Rice and Spice Aberdeen UK, in the form of broom units. Selection of healthy OPBF was carried out by visual inspection and handpicking, making sure that the fibres were free from blemishes with fibres of $1 \mathrm{~m}$ average length selected. Through visual observation, it was observed that OPBF possess an axial gradation in which the fibres are thickest and thinnest in cross sectional diameter at the head and tail respectively. For this reason, each fibre was cut into four (4) specimens, each of $150 \mathrm{~mm}$ length and grouped under four (4) categories. Category A were fibres $150 \mathrm{~mm}$ long starting from the petiole joint while category B were fibres $150 \mathrm{~mm}$ long beginning from the end of category A. Similarly, category $\mathrm{C}$ were fibres $150 \mathrm{~mm}$ long beginning from the end of category B and category D being fibres $150 \mathrm{~mm}$ long beginning from the end of category C (See Fig 2.1). This approach was employed to better understand possible variations in behaviour along the entire fibre length. Cross sectional areas of a total of 150 specimens were measured. Although fibre selection was random, fibres with blemishes were rejected. All OPBF used for this study were more than 365 days old after harvesting from the oil palm trees.

Cross sectional areas of the fibres were measured with the aid of a digital calliper with a precision of $0.01 \mathrm{~mm}$. Due to the varying shapes of the fibre cross sections, two diameter measurements were recorded for each 
cross-section and equivalent cross-sectional areas were determined assuming a circular cross-section. In order to determine the sufficiency of the sample size for determining standard cross sections, equation (2.1) prescribed by ASTM D2915-17 [1] was used.

$n=\left(\frac{t s}{\alpha x}\right)^{2}$

Where, $n$ is sample size, $s$ is standard deviation, $x$ is specimen mean value, $\propto$ is estimate of precision (0.05), and $t$ is value of statistic from Table 1 of ASTM D2915-17. Mean cross sectional area of OPBF calculated was $1.837 \mathrm{~mm}^{2}$ while standard deviation $s$ was determined as $0.546 \mathrm{~mm}^{2}$. Substituting appropriate values into equation 2.1 gives an $n$ value of 138 specimens for a $95 \%$ confidence level. Hence the number of specimens investigated for the determination of standard cross-sectional areas is sufficient.

\subsubsection{Moisture Content Test}

Moisture content determination was carried out in accordance to the requirement of ASTM D4442-16 [2]. The fibres were cut into lengths of $50 \mathrm{~mm}$ and placed in a metallic dish. The specimen was weighed and placed in an oven and set to $103^{\circ} \mathrm{C}$ for 24 hours. The OPBF was then weighed, then returned to the oven and re-weighed. This was repeated until a constant mass was achieved. Moisture content was calculated using equation 2.2:

$M C(\%)=\frac{w-w_{d}}{w_{d}} \times 100$

where; $w=$ original mass, and $w_{d}=$ oven-dry mass. The test was carried out on three batches of specimen and the average moisture content of the OPBF was determined as $9.86 \%$. It is recommended that oil palm fibres be dried to moisture content below $10 \%$ prior to their use to prevent fungal attack [3].

\subsubsection{Specific Gravity Determination}

The specific gravity of OPBF was determined according to the requirements of ASTM D854-14 [4]. The specimens were cut into lengths of 50mm with the aid of a pair of metallic scissors, so they can be put in a pycnometer. At a moisture content of $9.86 \%$, specific gravity of OPBF was found to be 0.84 . The low specific gravity makes it superior to steel in terms of strength-to-weight ratio. The specific gravity also helps for the determination of quantities during mix design for concrete as calculated volumes were converted into equivalent weights used for batching of materials for concrete. 


\subsubsection{Water Absorption Test}

This test is carried out to assess the behaviour of a material at proximity with water or moisture. This is especially important to understanding OPBF's impact on workability when included in fresh concrete. It also enhances understanding of fibre volume changes with the (un)availability of moisture. Strength of fibrereinforced concrete is enhanced by the bond strength between the fibres and the concrete. This bonding depends on the degree of dimensional stability of the fibres which is usually governed by fibre water absorption characteristics.

The fibres were cut into lengths of 50mm, weighed and placed in a plastic jar. Water was added to the specimen in the jar until the specimen was fully submerged and left to stand undisturbed at room temperature of $23^{\circ} \mathrm{C}$ for 24 hours. The fibres floated to the surface of the water at the beginning of the test due to their low specific weight. After 24 hours, the OPBF was then weighed until a constant mass was achieved. Water absorption was calculated using equation 2.3.

$$
W_{A}(\%)=\frac{w_{w e t}-w_{d r y}}{w_{d r y}} \times 100
$$

Where; $W_{\text {wet }}=$ wet mass of $O P B F$, and $W_{d r y}=$ natural mass of $O P B F$. The test was carried out on three batches of specimen and the 24 hours average water absorption of the OPBF was determined as $44.7 \%$. In a hardened concrete matrix however, the fibres may not absorb up to this quantity of moisture.

\subsubsection{Microscopic Examination}

In order to investigate and understand the shapes of fibre cross-section, fibre morphology and the nature of the failure surfaces of OPBF, microscopic examination of the fibres and fracture surfaces was carried out using an optical microscope. An observation of the fractured surfaces of OPBF reveals that the filaments making up each fibre are bonded by lignin of varying thickness. This, together with unevenly distributed phloems and xylems, is responsible for varying inter-filament bond strength. Under tension, the weakest bonds fail first and the stress is transferred unto another section of the fibre. As a result, a sudden brittle shear 
failure mode occurs at fracture for some of the samples (see Fig 2.1). Fig 2.2 presents optical microscopy of the 4-categories of OPBF cross section.

\subsubsection{Determination of Tensile Strength}

Tensile strength is a major indicator of the structural performance of a material. To avoid damage from the grips of the jaw of the testing machine, the ends of each fibre sample were dipped in epoxy glue and a bulb of glue was allowed to set on the sample ends for about 60 hours (see Fig 2.1). The bulb length was about $20 \mathrm{~mm}$ and $7 \mathrm{~mm}$ in length and thickness respectively. This resulted in a specimen gauge length of $110 \mathrm{~mm}$. The determination of tensile strength of OPBF was carried out on a Hounsfield universal testing machine (Model H10KS). Each fibre was inserted into the grips at the bulb ends and secured in a vertical position. The test was performed according to the requirements of ASTM D4761-13 [5] in displacement control at $5 \mathrm{~mm} / \mathrm{mm}$. Average test time for each fibre was 2 minutes. Results from fibres which failed prematurely by pulling-out at the hardened glue ends were discarded.

A total of 85 OPBF specimens were prepared and tested in tension. Specimens which generated extreme results were neglected and a stress-strain curve was obtained for each category of fibre. OPBF fails in a sudden brittle manner. Observation of the stress-strain curves show that failure is not pre-empted by warning. It is important to take this into consideration for design involving possible use of the fibre as reinforcement in concrete. The specimens failed at the point of smallest cross-section just before the epoxy grip end. Hence stress-strain calculations were based on the smallest cross-sectional areas of the fibres. Fig 2.3 presents the stress-strain relationships of the 4 categories of OPBF. The stress-strain relationships are based on the lowest cross-sectional area of each fibre since the fibres failed at this point.

Among the four categories of fibres tested, D-fibres recorded the highest tensile strengths while A-fibres recorded the lowest tensile strengths. An optical microscopy of the cross sections (Fig 2.2) explains this. The A-fibres which have cross-sectional areas in the range of $2.00-3.65 \mathrm{~mm}^{2}$ have filaments around their cortex lightly packed such that the cross-section is dominated with cavities in the range of $100,000-140,000 \mu \mathrm{m}^{2}$ in cross section. As one proceeds from the top down the length of the fibre, the cross-section area reduces but a denser filament packing is observed with cavities ranging between $1500-7000 \mu \mathrm{m}^{2}$. Therefore, whereas, fibres with larger cross-sections are expected to have better strength, the effective area of cross-section 
resisting axial tension is relatively lower than that of the fibres with smaller cross-sections. The grading of cavity size along the length of the oil palm broom leaflet makes the broom fibres a naturally functionally graded material (NFGM) [52]. The increase in cavity towards the cap of the fibres creates a truss system which is biologically engineered and causes the fibre to bear increased bending moments caused by the action of wind incident upon the leaflets. This radial and longitudinal density gradient is responsible for the phenomenon whereby the fibres are stiffer in bending towards the head but possess lesser strength in tension and hence explains the lower tensile strength observed for the fibre categories with larger cross-sections, towards the head of the fibre.

From the tensile test data recorded from the test, OPBF have a mean tensile strength and elastic modulus of 372MPa and 8GPa respectively. The strength data show a standard deviation of 166.41 and standard error of 18.05. Specimen preparation for tensile test was a herculean task as the ends of each fibre need be cleaned with the aid of fine sandpaper in a bid to properly bond with the epoxy glue. Secondly, the process of cleaning the ends reduced the fibre cross-section and such fibres failed prematurely at the point just before the hardened glue. Stress-strain relationships for the 4-categories of fibres are presented in Fig 2.3.

\subsection{OPBF-Concrete}

A total of one hundred and ten (110) samples of 63 cubic, 21 cylindrical and 21 prismatic OPBF-concrete specimens were cast to assess compressive, flexural and splitting tensile strengths. Bonding between OPBF and concrete was also assessed through a direct pull-out test where the OPBF was pulled out of the matured (hardened) concrete cubes after 28 days. A total of 5 specimens of OPBF inserted-concrete cubes were prepared. General purpose limestone cement (Blue Circle) was used as the binder while sand and gravel all obtained from Jewson Ltd UK were used as the aggregates. Particle size distribution analysis was carried out on the aggregates according to ASTM D2487. The fine aggregate was graded as medium sand while the coarse aggregate was graded as fine gravel. The distribution grading curves are presented in Fig 2.4c.

After a trial mix on 9 samples in which the fine aggregate to coarse aggregate ratio was varied, the mix design ratio of 1:1.5:3 was chosen for cement, sand and gravel respectively with a target concrete strength of 35 MPa at 28 days for $(100 \times 100 \times 100)$ mm cubic specimens. This grade of concrete chosen is the typical concrete grade used for residential building construction. An electrically-powered rotating drum concrete mixer of 30 
litres mix capacity was used in the mixing of the aggregates and binder. For each mix ratio, 9-(100x100x 100) mm cubes, 3-(100x200) mm cylinders and 3-(100x100x500) mm beams were cast. The cubes were tested for compressive strength at 7,14 and 28 days while the cylinders and beams were tested for splitting tensile strength and flexural strength respectively at 28 days. OPBF was cut into lengths of $50 \mathrm{~mm}$ with the aid of a pair of metallic scissors and included randomly in the concrete by partially replacing the total aggregates volume at $0.5 \%, 1 \%, 1.5 \%, 2 \%, 3 \%$ and $4 \%$. Using a target water cement ratio of 0.53 for the control concrete, half of the measured water was first poured into the mixer followed by the coarse aggregate, the fine aggregate and finally the cement. This was allowed to mix for about 4 minutes before the remaining water was gradually added until a consistent mix was achieved after another 4 minutes of mixing. This procedure was adhered to for all sample preparation and conforms to ASTM C192/C192M - 02 [6]. For the OPBFconcrete mix, the respective fibre quantities were measured and added after proper mixing of the mineral aggregates. A further 3 minutes was allowed for the proper mixing of the fibres in the fresh concrete.

At the desired workability (assessed through slump testing) the fresh concrete was poured into standard metallic moulds whose interiors were already smeared with spent motor-oil. Oiling the mould is important for easy de-moulding of the concrete samples after hardening. The moulds were filled in half, vibrated for 20 seconds, filled up and further vibrated for another 10 seconds to ensure good compaction of the samples. At approximately 24 hours, the samples were demoulded, weighed, labelled using a permanent black marker and placed in a water tank in the laboratory to ensure sufficient hydration of the concrete before testing. The dimensions of all samples were measured in order to derive stress and strain from the force-displacement data provided by the test machines. For the direct pull-out (bond) test, $150 \mathrm{~mm}$ long OPBF were inserted into fresh concrete in the $(100 \times 100 \times 100)$ mm cubic moulds such that the embedded length of the OPBF in the concrete is 50mm. Details of the specimen set-up for bond (pull-out) test are presented in Fig 2.5.

\subsubsection{Workability}

Generally, workability of fresh concrete reduces with increase in fibre content due to the characteristic water absorption of vegetable fibres [7, 8, 9, 10, 11, 10]. Mazlan and Awal [12] and Musa et al. [13] attributed reduced workability to the increase in the surface area of the fibre aggregates and high-water absorption of natural fibres making less water available for the mix. This is partly true for OPBF. From the optical 
microscopy of OPBF surface, a tightly-structured cell wall is observed. This may be responsible for OPBF not absorbing water readily in the short term (i.e. during mixing of concrete). Secondly, OPBF is stiff and does not create balling-effects (or intertwining due to mechanical disturbance) and hence does not trap water within the "ball" as is the case with typical with flexible vegetable fibres. The major points of entry of moisture into the fibre are the cut ends. Increase in OPBF amount only required slight increase in the amount of water needed to achieve the required slump. Increase in water demand by the OPBF-concrete is mainly due to increased surface area of the aggregates for the higher inclusion amount of OPBF. Measurement of workability is presented here in terms of water-cement ratio (Fig 2.6b). All water-cement ratios for the respective volume replacement of aggregate volume by OPBF were determined to acquire a target slump of between $80-100 \mathrm{~mm}$ (see Fig 2.6a). The slump tests were carried out according to the requirements of the standard test method for slump of hydraulic-cement concrete-ASTM C143/C143M-15a [14].

\subsubsection{Compressive Test}

All control concrete and OPBF-concrete samples were tested in an Instron-8500 machine. The tests on concrete specimens were carried out in displacement control at the rate of $3 \mathrm{~mm} / \mathrm{min}$. The compressive strength of OPBF-concrete was performed on 100x100x100mm cubic samples. Compressive strength was obtained for a reference age of 7, 14 and 28 days. Fig 2.7 presents the compressive strength results. OPBF inclusion in concrete reduces compressive strength. This reduction in strength does not corroborate the findings of Shareef and Ramli [15] and Ahmad et al [16] for inclusion of other oil palm fibres in concrete. The reduction in compressive strength is due to the relative low stiffness of OPBF. This creates weak planes of failure for the much harder matrix. The reduction in compressive strength is proportional to the amount of OPBF inclusion in the matrix. Reduction in compressive strength of $2.9 \%, 5.5 \%, 15.4 \%, 21.5 \%, 18.9 \%$ and $32 \%$ were recorded for $0.5 \%, 1 \%, 1.5 \%, 2 \%, 3 \%$, and $4 \%$ volume inclusion of OPBF at 28 days maturity.

\subsubsection{Splitting Tensile Test}

Splitting tensile test was performed on 100x200mm cylindrical specimens with replacement of total aggregate volume at $0.5,1.0,1.5,2.0,3.0$ and $4.0 \%$. The test was carried out according to the requirements of ASTM C496/C496M-17 [17]. Splitting tensile strength was calculated using equation 2.4.

$f_{t}=\frac{2 P}{\Pi l d}$ 
Where $f$ is splitting-tensile strength $(M P a), P$ is maximum load at failure $(N), l$ is height of cylindrical sample and $d$ is diameter of sample. With increase in the inclusion of OPBF, splitting tensile strength reduced (Fig 2.8). Two main reasons could responsible for this reduction. Firstly, the splitting tensile test is compressive in nature and the relatively low stiffness and elastic modulus of the OPBF creates weak planes within the matrix. The tendency of the fibres to agglomerate at the top of the samples during vibration because of low specific weight of OBPF (Fig 2.9c) was also another reason, however this was taken care of by limiting the water-cement ratio to between $0.53-0.56$. Sudden brittle failure was prevented by the bridging action of the OPBF. Fig 2.9a shows failed OPBF-concrete samples whose splits have been deliberately expanded to expose OPBF crack-bridging effect.

\subsubsection{Flexural Test}

This test evaluated the modulus of rupture of the beam samples. A total of 21-(100x100x500) mm beam samples were prepared. The determination of flexural strength was carried out in accordance with the standard test method for flexural performance of fibre-reinforced concrete (using beam with third-point loading) ASTM C1609/C1609M-12 [18]. Data acquisition was carried out with the aid of a low voltage displacement transducer (LVDT) connected to a data logger and computer (see Fig 2.10a). The first-peak strength was determined from the first peak-load by using equation 2.5 .

$f=\frac{P L}{b d^{2}}$

Where; $f$ is flexural strength in $M P a, P=$ Maximum load in Newton, $L=$ the span in $m m, b$ is the average width of the specimen at the fracture, as oriented for testing in $m m$ and $d$ is the average depth of the specimen at the fracture, as oriented for testing in $\mathrm{mm}$.

Fig 2.11 and 2.12 presents the graphs of load vs midspan deflection and flexural (yield) strength vs volume replacement of OPBF respectively. Optimum volume inclusion is $1 \%$ OPBF with $4 \%$ improvement in flexural strength and $41 \%$ increase in midspan deflection. Although the improvement in flexural strength is negligible, the stress-strain relationship presented in Fig 2.11 shows that increase in OPBF leads to increase in the energy absorption capacity of the samples. Increased energy absorption means that the OPBF sample have a better post-yield response to dynamic excitation. Fig 2.10(d) reveals that specimen failure was characterized by more fibre pull-outs than fibre fracture. 


\subsubsection{Flexural Toughness}

Toughness is the ability of a material to absorb energy and plastically deform without fracturing. Toughness as a material property can gives an indication of post-yield performance of a structural member which is sought after for seismic-resistant structures. Toughness is defined as the area under the stress-strain curve of a material. In this study, Flexural toughness of OPBF-concrete was assessed relative to the control concrete at 28 days and presented as Toughness Index which is defined in equation 2.6. Fig 2.11 was used directly to calculate the respective areas under each curve since assessment of energy absorbed was carried out in terms of Toughness Index.

Tougness Index $=\frac{\text { Flexural toughness of OPBF-concrete }}{\text { Flexural toughness of control concrete }}$

The control beams were broken into two pieces in a brittle manner at maximum load. However, OPBF-beams were held together even after failure. Fig $2.9 \mathrm{~d}$ and $2.10 \mathrm{~d}$ shows the cross-section of OPBF-beams and cylinders which have been intentional broken into two halves to observe the mode of fibre failure. Although fibre-pull out was the major failure mode observed, fibre-fracture was also noticed for a few samples. The mechanism for energy dissipation can therefore be attributed to pull-out of OPBF from the concrete matrix. Fibre pull-out is also an indication of poor bonding between fibre and matrix due to degradation of fibre surface. Santos et al [49] explains the degradation in vegetable fibre durability to the migration of cement hydration products into the fibres during water absorption inside the concrete matrix, thereby embrittling the OPBF. Wei and Meyer [50] also corroborates this occurrence for natural fibres reinforced cementitious composites. Fig 2.13 show the graph of toughness index $v s$ percentage inclusion of OPBF in concrete.

Fig 2.11 is the curve of flexural (yield) strength vs midspan deflection at 28 days respectively for various percentage inclusion of OPBF. The area under each curve represents the energy absorption capacity of OPBFconcrete. An increase in energy absorption capacity of the beams with increase in percentage volume of OPBF was observed. At 4\% OPBF inclusion, energy absorption increased by $500 \%$ at 28 days (see Fig 2.13), thereby making the use of OPBF-concrete in earthquake resistant construction promising at least for developing countries. An increased energy absorption implies enhanced energy dissipation, force redistribution and lower dynamic amplification of structural response to ground vibration [51]. Ductile performance is a sought-after characteristic for seismic-resistant concrete materials. 


\subsubsection{Direct Pull-out (Bond) Test}

The specimens were prepared by first cutting OPBF fibres into lengths of $150 \mathrm{~mm}$. For each fibre, one end was dipped in freshly prepared epoxy glue and allowed to harden in the form of a bulb. This was done to avoid damage from the grips of the machine during the fibre-pull-out test. A thin sheet of cello tape was used to wrap the fibre from the end of the epoxy bulb down to $50 \mathrm{~mm}$ to the fibres' free end. This was done to prevent the OPBF to minimise water absorption by the OPBF when immersed in water for curing. After this, petroleum jelly was applied around the cello tape to avoid it bonding with the concrete. The fresh concrete mix (1:1.5:3) was poured into the metallic moulds of 100x100x100mm to about half full. The prepared OPBF free end was inserted into the concrete and held in position with one hand while using the other hand to pour in the fresh concrete with a hand trowel. The prepared specimens were transferred unto a vibrating table and then vibrated in turns with the OPBF still held in possession leaving 50mm OPBF length in the concrete. The pull-out test was carried out on a Hounsfield machine with a $3 \mathrm{kN}$ load cell in displacement control at $5 \mathrm{~mm} / \mathrm{min}$. Fig 2.5 shows the test set up. Assuming a uniform bond, the bond strength was defined as follows (equation 2.7);

$u=\frac{P_{\max }}{d_{b} L_{b}}$

Where; $P_{\max }$ is maximum pullout load, $d_{b}$ is diameter of fibre crossection and $L_{d}$ is the embedded fibre length. A total of five (5) specimens was prepared and tested for 28days. Average bond strength was determined as $0.78 \mathrm{MPa}$. All OPBF pulled out of the concrete matrix without damage to the fibres. Reasons for poor bond strength between the fibres and the matrix may include weak smooth OPBF surface and dimensional instability due to water absorption of the natural fibre during curing. However, treatments such as alkalisation, acetylation, boiling, silane treatment and coating of the fibre surfaces with water-proof resins have been reported to enhance hydrophobic and mechanical properties of oil palm fibres [32,42,52]. Machaka et al. [53] recommended a $4 \% \mathrm{NaOH}$ for alkali treatment of fan palm fibres for inclusion in concrete as higher concentration of alkali caused reduction of $23-30 \%$ of the fibre thickness. Although the mechanical properties of the fibres were 
not improved in the study, roughness and hydrophobicity of the fibres were improved and could enhance fibre-concrete bonding.

\subsection{Prediction of Compressive Strength}

From the results obtained, it is necessary to establish a relationship between the amount of OPBF inclusion, age and compressive strength in OPBF-concrete. This could also enhance understanding of the timedependent performance of OPBF in concrete. Hence multiple regression analysis was carried out using Matlab $2014 a$ software in which equation 3.1b was derived with compressive strength as a function of percentage volume of OPBF inclusion and age of the concrete sample. The relationship between the three variables can be represented with the second-degree polynomial in equation 3.1a [54]:

$$
f\left(x_{i}, x_{j}\right)=\alpha_{0}+\sum_{i=1}^{k} \alpha_{i} x_{i} \sum_{i=1}^{k} \alpha_{i i} x_{i}^{2}+\sum_{i<1}^{k} \alpha_{i j} x_{i} x_{j}
$$

Which is translated into equation $3.1 \mathrm{~b}$ as;

$f_{c}\left(x_{1}, x_{2}\right)=\alpha_{0}+\alpha_{1} x_{1}+\alpha_{2} x_{1}^{2}+\alpha_{3} x_{1} x_{2}+\alpha_{4} x_{2}+\alpha_{5} x_{2}^{2}$

Where, $x_{1}$ is Age of concrete sample in days, $x_{2}$ is Amount of OPBF in percentage volume of total aggregate $f_{c}(x, y)$ is compressive strength (MPa), while, $\alpha_{0}, \alpha_{1}, \alpha_{2}, \alpha_{3}, \alpha_{4}$ and $\alpha_{5}$ are non-dimensional coefficients whose values are found in Table 3.1. $\alpha_{0}$ is the intercept, $\alpha_{1}$ and $\alpha_{4}$ are the linear coefficient, $\alpha_{2}$ and $\alpha_{5}$ are the quadratic coefficients and $\alpha_{3}$ is the interaction coefficient.

The value of the adjusted coefficient of determination (Table 3.1) implies that the age of the concrete and the percentage amount of OPBF inclusion are mostly responsible (up to 92.8\%) for the prediction of compressive strength. The relationship between the mechanical properties of OPBF-concrete can be further explored and refined by testing samples beyond 28 days. Fig 3.1 presents a response surface plot of the model relationship between compressive strength, OPBF content and age of concrete with the latter two as predictor variables.

Table 3.1: Response surface table of statistics

\begin{tabular}{|c|c|c|c|c|c|}
\hline $\begin{array}{l}\text { Regression } \\
\text { Coefficients }\end{array}$ & Value & $\mathbf{R}^{2}$ & $\begin{array}{c}\mathbf{R}^{2} \\
\text { (Adjusted) }\end{array}$ & $\begin{array}{l}\text { sum of squared } \\
\text { errors (SSE) }\end{array}$ & $\begin{array}{c}\text { Root Mean Square } \\
\text { Error (RMSE) }\end{array}$ \\
\hline$\alpha_{0}$ & 31.98 & & & & \\
\hline
\end{tabular}




\begin{tabular}{|c|c|c|c|c|c|}
\hline$\alpha_{1}$ & 3.457 & & & & \\
\hline$\alpha_{2}$ & -6.016 & 0.9456 & 0.9275 & 45.03 & 1.733 \\
\hline$\alpha_{3}$ & -0.1595 & & & & \\
\hline$\alpha_{4}$ & -0.5646 & & & & \\
\hline$\alpha_{5}$ & 1.821 & & & & \\
\hline
\end{tabular}

\subsection{CONCLUSION}

This study assessed some physical and mechanical properties of OPBF, compressive strength, flexural strength, splitting tensile strength and toughness of OPBF-concrete. Bond strength between OPBF and concrete was also assessed through pull-out test. Discrete OPBF fibres of 50mm length was introduced randomly in concrete to assess suitability of the vegetable fibre in concrete. Finally, an attempt was made to predict compressive strength of OPBF at 28 days using a $2^{\text {nd }}$-degree polynomial model that uses percentage amount of OPBF inclusion and age of OPBF-concrete as predictor variables. Consequently, the following conclusions are made:

- Inclusion of discrete OPBF reduces workability of fresh concrete,

- $\quad$ OPBF reduces compressive strength and splitting tensile strength of concrete, but can improve flexural strength by $4 \%$,

- Optimal volume inclusion and length of OPBF in concrete is $1 \%$ and $50 \mathrm{~mm}$ respectively with an increased energy absorption of $93 \%$ at 28 days,

- $\mathrm{OPBF}$ is the stiffest amongst oil palm fibres,

- $\mathrm{OPBF}$ is superior to steel in terms of strength/weight ratio,

- $\quad$ Failure of OPBF-concrete is characterised by more fibre pull-outs than fibre-fractures,

- $\quad$ OPBF inclusion in concrete improves energy absorption capacity of the resulting concrete making it a cheap potential material for anti-seismic construction.

- $\quad$ OPBF is also suitable in concrete as short discrete fibre-reinforcement in, roofing tiles, building bricks, lintel beams, building claddings and facades, 
- Due to the low specific weight of OPBF, prolonged vibration of the OPBF-concrete leads to agglomeration of OPBF at the top of the sample. Consequently, water-cement ratio of OPBF concrete should not exceed 0.56 .

- Testing of OPBF-concrete beyond 28 days is necessary to investigate age-dependent integrity of the vegetable fibres in the concrete matrix.

Processing of OPBF for incorporation in concrete is eco-friendly, cheap and can lead to reduction in construction cost and time and provide employment opportunities.

\section{Funding}

The authors wish to thank the Nigerian Petroleum Technology Development Fund (PTDF) of Nigeria for sponsoring this study.

\section{References}

[1] F. Asdrubali, F. D'Alessandro and S. Schiavoni, "A review of unconventional sustainable building insulation materials," Sustainable Materials and Technologies, vol. 4, pp. 1-17, 2015.

[2] J. Page, F. Khadraoui, M. Boutouil and M. Gomina, "Multi-physical properties of a structural concrete incorporating short flax fibers," Construction and Building Materials, vol. 140, pp. 344-353, 2017.

[3] J. Claramunt, F.-C. J. Lucía, H. Ventura and M. Ardanuy, "Natural fiber nonwoven reinforced cement composites as sustainable," Construction and Building Materials, pp. 230-239, 2016.

[4] M. Ardanuy, J. Claramunt and R. D. Toledo Filho, "Cellulosic fiber reinforced cement-based composites: A review of recent research," Construction and Building Materials, vol. 79, pp. 115-128, 2015.

[5] H. A. Colorado and A. Loaiza, "Portland cement paste blended with pulverized coconut fibers," Advances in Materials Science for Environmental and Energy Technologies, vol. 6, pp. 79-84, 2017.

[6] G. Ramakrishna and T. Sundararajan, "Impact strength of a few natural fibre reinforced cement mortar slabs: a comparative study," Cement and Concrete Composites, vol. 27, no. 5, pp. 547-553, 2005 .

[7] R. G. Elenga, G. F. Dirras, J. G. Maniongui, P. Djemia and M. P. Biget, "On the microstructure and physical properties of untreated raffia textilis fiber," Composites Part A: Applied Science and Manufacturing, vol. 40, no. 4, pp. 418-422, 2009. 
[8] I. O. Oladele, J. A. Omotoyinbo and J. O. T. Adewara, "Investigating the effect of chemical treatment on the constituents and tensile properties of sisal fibre," Journal of Minerals and Minerals Characterisation and Engineering, vol. 9, no. 6, pp. 569-582, 2010.

[9] A. Agarwal, B. Nanda and D. Maity, "Experimental investigation on chemically treated bamboo reinforced concrete beams and columns," Construction and Building Materials, vol. 71, pp. 610-617, 2014.

[10] M. Asim, K. Abdan, M. Jawaid, M. Nasir, Z. Dashtizadeh, M. R. Ishak and M. E. Hoque, "A review on pineapple leaves fibre and its composites," International Journal of Polymer Science, pp. 1-16, 2015.

[11] A. Agopyan, H. J. Savastano, V. M. John and M. A. Cincotto, "Developments on vegetable fibrecement based materials in Sao Paulo, Brazil: an overview," Cement and Concrete Composites, vol. 27, no. 5, pp. 527-536, 2005.

[12] P. S. A. Lertwattanaruk, "Properties of natural fiber cement materials containing coconut coir and oil palm fibers for residential building applications," Construction and Building Materials, vol. 94, no. 1, pp. 664-669, 2015.

[13] N. Benmansour, B. Agoudjil, A. Gherabli, A. Kareche and A. Boudenne, "Thermal and mechanical performance of natural mortar reinforced with date palm fibers for use as insulating materials in buildings," Energ and Buildings, vol. 81, pp. 98-104, 2014.

[14] S. K. Al-Oraimi and A. C. Seibi, "Mechanical characterisation and impact behaviour of concrete reinforced with natural fibres," Composite Structures, vol. 32, no. 1-4, pp. 165-171, 1995.

[15] S. Ismail and Z. Yaacob, "Properties of laterite bricks reinforced with oil palm empty fruit bunch fibres," Pertanika Journal of Science and Technology, pp. 22-43, 2011.

[16] J. Balasubramanian and S. S. Selvan, "Experimental Investigation of natural fibre reinforced concrete in construction industry," International Research Journal of Engineering and Technology, vol. 2, no. 1, pp. 199-182, 2015.

[17] M. A. Seixa, L. A. Ripper and K. Ghavani, "Deployable bamboo structure for sustainable architecture," in 15th International Conference on non-conventional Materials and Technologies, 2014.

[18] E. O. Momoh and B. I. Dahunsi, "Suitability of Oil-Palm-Broom-Fibres as Reinforcement for Laterite-based Roof Tiles," International Journal of Software \& Hardware Research in Engineering, vol. 5, no. 4, pp. 27-35, 2017.

[19] A. H. P. S. Khalil, M. Jawaid, A. Hassan, M. T. Paridah and A. Zaidon, "Oil Palm Biomass Fibres and Recent Advancement in Oil Palm Biomass Fibres Based Hybrid Biocomposites," in Composites and Their Applications, United Kingdom, IntechOpen, 2012, pp. 187-220.

[20] M.S.Sreekala, J. George, M. G. Kumaran and S. Thomas, "The mechanical performance of hybrid phenol-formaldehyde-based composites reinforced with glass and oil palm fibres," Composites Science and Technology, vol. 62, no. 3, pp. 339-353, 2002. 
[21] R. Dungani, M. Jawaid, H. P. S. Abdul Khalil, J. Jasni, S. Aprilia, K. R. Hakeem, S. Hartati and M. N. Islam, "A Review on Quality Enhancement of Oil Palm Trunk Waste by Resin Impregnation: Future Materials," Bioresources, vol. 8, no. 2, pp. 3136-3156, 2013.

[22] M. S. Sreekala, M. G. Kumaran, S. Joseph, M. Jacob and S. Thomas, "Oil palm fibre reinforced phenol formaldehyde composites: influence of fibre surface modifications on the mechanical performance," Applied Composite Materials, vol. 7, no. 5-6, pp. 295-329, 2000.

[23] O. Ofuyatan and F. Olutoge, "Flexural characteristics and potentials of oil palm stem as reinforcementin concrete beams," Journal of Emerging Trends in Engineering and Applied Sciences, vol. 4, no. 4, pp. 642-647, 2013.

[24] Z. Ahmad, H. M. Saman and P. M. Tahir, "Oil palm trunk fiber as a bio-waste resource for concrete reinforcement," International Journal of Mechanical and Materials Engineering, vol. 5, no. 2, pp. 199-207, 2010.

[25] S. Shinoj, R. Visvanathan, S. Panigrahi and M. Kochubabu, "Oil palm fiber (OPF) and its composites: a review," Industrial Crops and Products, vol. 33, no. 1, pp. 7-22, 2011.

[26] F. Owolabi, A. W. Taiwo, A. F. M. Alkarkhi and A. Ghazali, "Optimization of the Strength Properties of Waste," Journal of Natural Fibers, vol. 14, no. 4, pp. 551-563, 2017.

[27] E. T. D. Shareef and M. B. Ramli, "Study on The Effect Of Using Palm Fiber On The Properties Of High Strength Flowable Mortar," in 34th conference on our world in concrete \& structures, Singapore, Singapore, 2009.

[28] J. Kaliwon, S. S. Ahmad and A. A. Aziz, "Performance of oil palm EFB fibre reinforced concrete roof slates," in International Conference on Science and Social Science Research (CSSR), 2010.

[29] K. H. Or, A. Putra and M. Z. Selamat, "Oil palm empty fruit bunch fibres as sustainable acoustic absorber," Applied Acoustics, vol. 119, pp. 9-16, 2017.

[30] H. Danso, "Properties of Coconut, Oil Palm and Bagasse Fibres: As Potential Building Materials," in 3rd Internation Conference on Natural Fibers: Advanced Materials for a Greener World, ICNF 2017, 21-23 June 2017, Braga, Portugal, Procedia Engineering.

[31] R. Zulkifli, M. J. M. Nor, A. R. Ismail , M. Z. Nuawi, S. Abdullah, M. F. M. Tahir and M. N. AbRahman, "Comparison of acoustic properties between coir fibre and oil palm fibre," European Journal of Scientific Research, vol. 33, no. 1, pp. 144-152, 2009.

[32] N. G. Ozerkan, B. Ahsan, S. Mansour and S. R. Iyengar, "Mechanical performance and durability of treated palm fiber reinforced mortars," International Journal of Sustainable Built Environment, vol. 2, no. 2, pp. 131-142, 2013.

[33] E. O. Momoh and A. I. Osofero, "Recent Developments in the Application of Oil Palm Fibres in Cement Composites," Frontiers of Structural and Civil Engineering, no. Accepted, 2019.

[34] B. Nduka, "Development of abrasive selection model/chart for palm frond broom peeling machine design," International Journal of Engineering Research and Applications, pp. 84-90, 2014. 
[35] "ASTM D2915 - 17: Standard Practice for Sampling and Data-Analysis for Structural Wood and Wood-Based Products".

[36] "ASTM D4442-16: Standard Test Methods for Direct Moisture Content Measurement of Wood and Wood-Based Materials".

[37] I. Puspasari, M. Z. M. Talib, W. R. W. Daud and S. M. Tasirin, "Characteristic drying curve of oil palm fibers," International Journal on Advanced Science, Engineering and Information Technology, vol. 4, no. 1, pp. 20-24, 2014.

[38] "ASTM D854-14: Standard Test Methods for Specific Gravity of Soil Solids by Water Pycnometer".

[39] "ASTM D4761-13: Standard Test Methods for Mechanical Properties of Lumber and Wood-Base Structural Material".

[40] "ASTM C192/C192M-02: Standard Practice for Making and Curing Concrete Test Specimens in the Laboratory".

[41] R. A. Olaoye, J. R. Oluremi and S. O. Ajamu, "The use of fibre waste as complement in concrete in concrete for a sustainable environment," Innovative Systems Design and Engineering, vol. 4, no. 9, pp. 91-97, 2013.

[42] M. S. Sreekala, M. G. Kumaran and S. Thomas, "Oil Palm Fibers: Morphology, Chemical Composition, Surface Modification, and Mechanical Properties," Journal of Applied Polymer Science, vol. 66, no. 5, pp. 821-835, 1997.

[43] D. Mazlan and A. S. M. Abdul Awal, "Properties of Cement based Composites containing Oil Palm Stem as Fiber Reinforcement," Malaysian Journal of Civil Engineering, pp. 107-117, 2012.

[44] A. G. Musa, N. Rajoria and A. G. Mohammed, "Effect of palm oil fiber on laterized concrete," International Journal of Engineering Technology, Management and Applied Sciences, vol. 5, no. 5, pp. 686-695, 2017.

[45] "ASTM C143/C143M-15a: Standard Test Method for Slump of Hydraulic-Cement Concrete".

[46] Z. Ahmad, A. Ibrahim and P. Tahir, "Drying shrinkage characteristic of concrete reinforced with oil palm trunk fiber," International Journal of Engineering Science and Technology, vol. 2, no. 5, pp. $1441-1450,2010$.

[47] "ASTM C496/C496M-17: Standard Test Method for Splitting Tensile Strength of Cylindrical Concrete Specimens".

[48] "ASTM C1609/C1609M-12: Standard Test Method for Flexural Performance of Fiber-Reinforced Concrete (Using Beam With Third-Point Loading)".

[49] S. F. Santos, G. H. D. Tonoli, J. E. B. Mejia, J. Fiorelli and H. Savastano Jr, "Non-conventional cement-based composites reinforced with vegetable fibers: A review of strategies to improve durability," Materiales de Construccion, vol. 65, no. 317, 2015. 
[50] J. Wei and C. Meyer, "Degradation mechanisms of naturalfiber in the matrix ofcement composites," Cement and Concrete Research, vol. 73, pp. 1-16, 2015.

[51] E. O. Momoh and K. Pilakoutas, "Highly Deformable Energy-Dissipating Reinforced Concrete Elements in Seismic Design of Reinforced Concrete Structures," International Journal of Engineering Research and Applications, vol. 7, no. 6, pp. 14-20, 2017.

[52] M. N. Izani, M. T. Paridah, U. M. K. Anwar, M. M. Nor and P. S. H'ng, "Effects of fiber treatment on morphology, tensile and gravimetric analysis of oil palm empty fruit bunches fibers," Composites Part B: Engineering, vol. 45, no. 1, pp. 1251-1257, 2013.

[53] M. Machaka, H. Basha, H. A. Chakra and A. Elkordi, "Alkali treatment of fan palm natural fibers for use in fiber reinforced concrete," European Scientific Journal, vol. 10, no. 12, pp. 186-195, 2014.

[54] D. C. Montgomery and R. H. Myers, Response Surface Methodology, Process and Product Optimization using Design Experiments, 2nd Ed, New York: John Wiley, 2004.

[55] L. C. Roma Jr, L. S. Martello and H. Savastano Jr, "Evaluation of mechanical, physical and thermal performance ofcement-based tiles reinforced with vegetable fibers," Construction and Building Materials, vol. 22, pp. 668-674, 2008. 


\section{Use of Oil Palm Broom Fibres for Eco-friendly Concrete}

Emmanuel Owoichoechi Momoh ${ }^{1}$ Adelaja Israel Osofero ${ }^{2}$

School of Engineering, University of Aberdeen, Kings College, Aberdeen, United Kingdom ${ }^{1,2}$

\section{Figures}

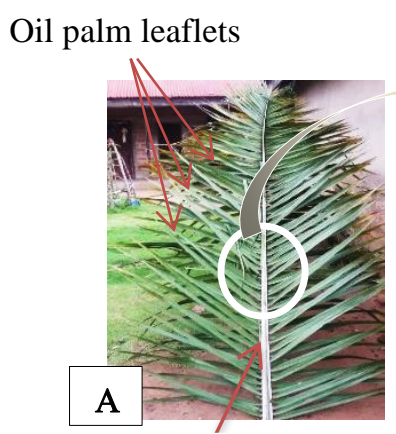

Petiole (frond)

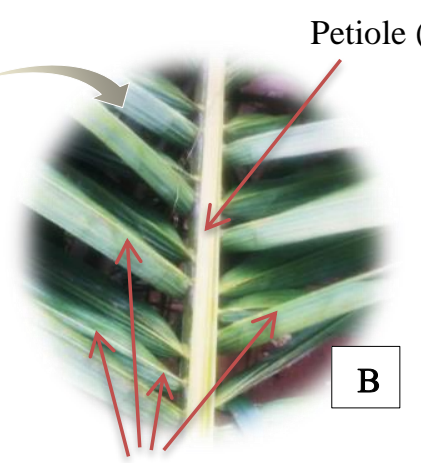

Ribs of oil palm leaflets

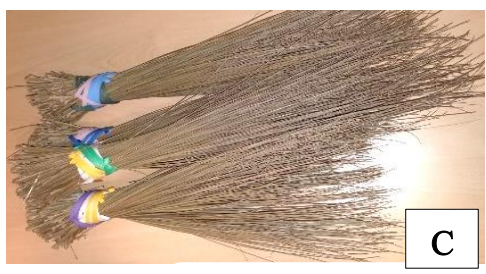

Brooms

Fig 1.1: Illustration of OPBF (A) oil palm leaf (B) magnified image of oil palm leaf (C) OPBF tied into broom
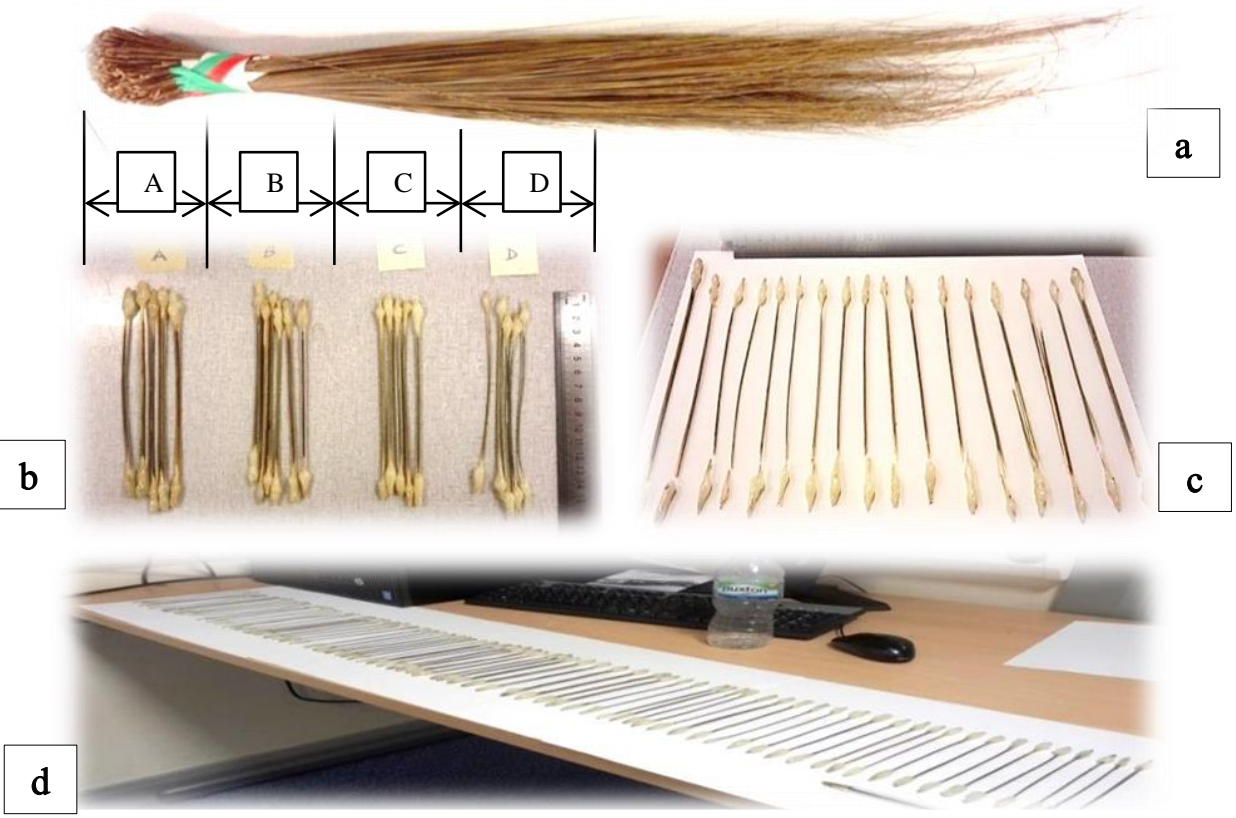

Fig 2.1: (a) Broom unit of 200 OPBF. (b) Illustration of the 4 fibre categories. (c) Failed OPBF samples at points of smallest cross-sections. (d) Some prepared OPBF samples for tensile tests. 

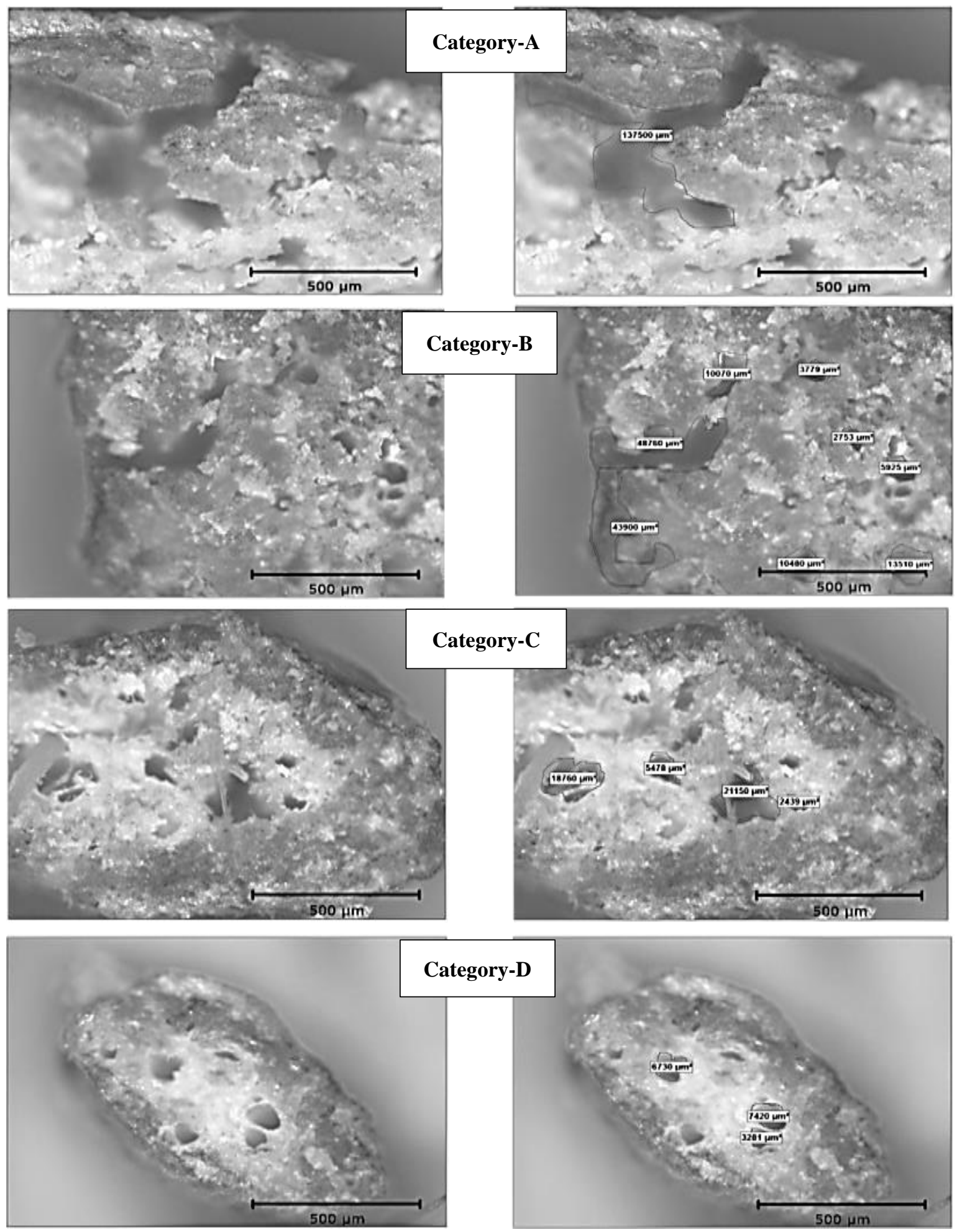

Fig 2.2: Optical microscopic examination of fresh oil palm broom fibre cross-sections

Cross-section (magnification 50X) (left). Area measurements of xylem cavities (right) 400X 

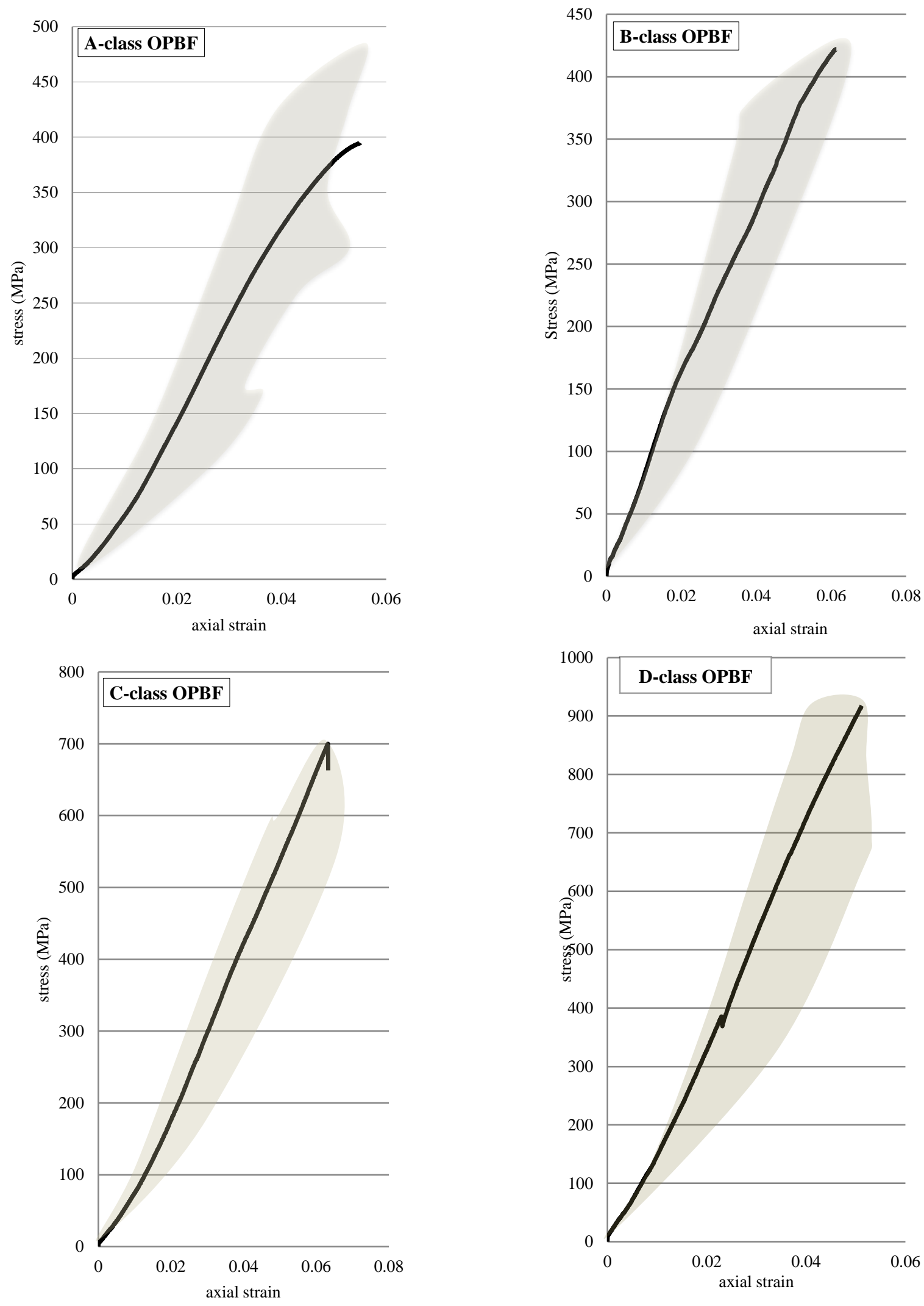

Fig 2.3: Stress-strain envelops of the four categories of OPBF 

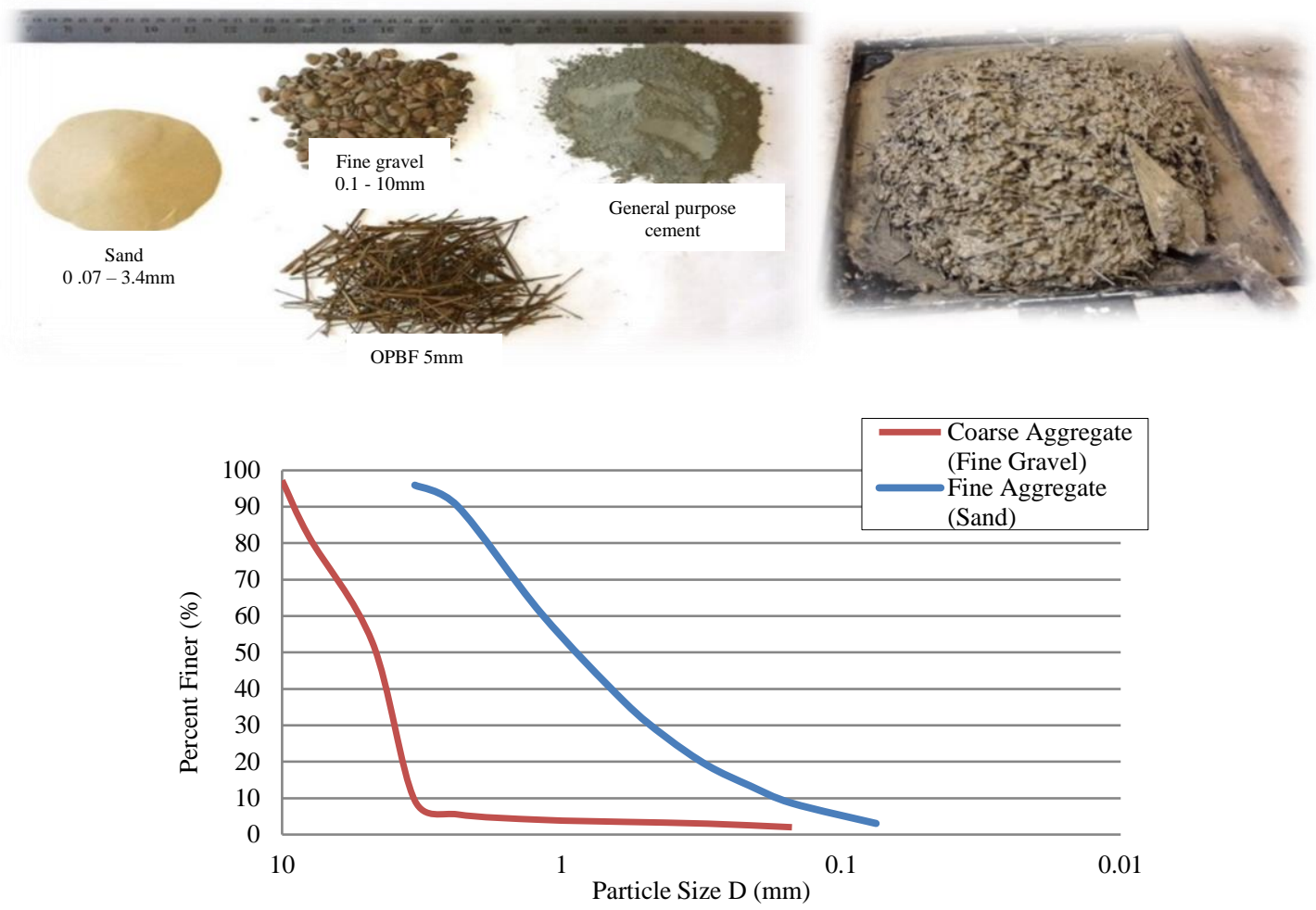

Fig 2.4: (a) OPBF-concrete constituents (b) Fresh OPBF-Concrete (c) Grading curves of fine and coarse aggregates

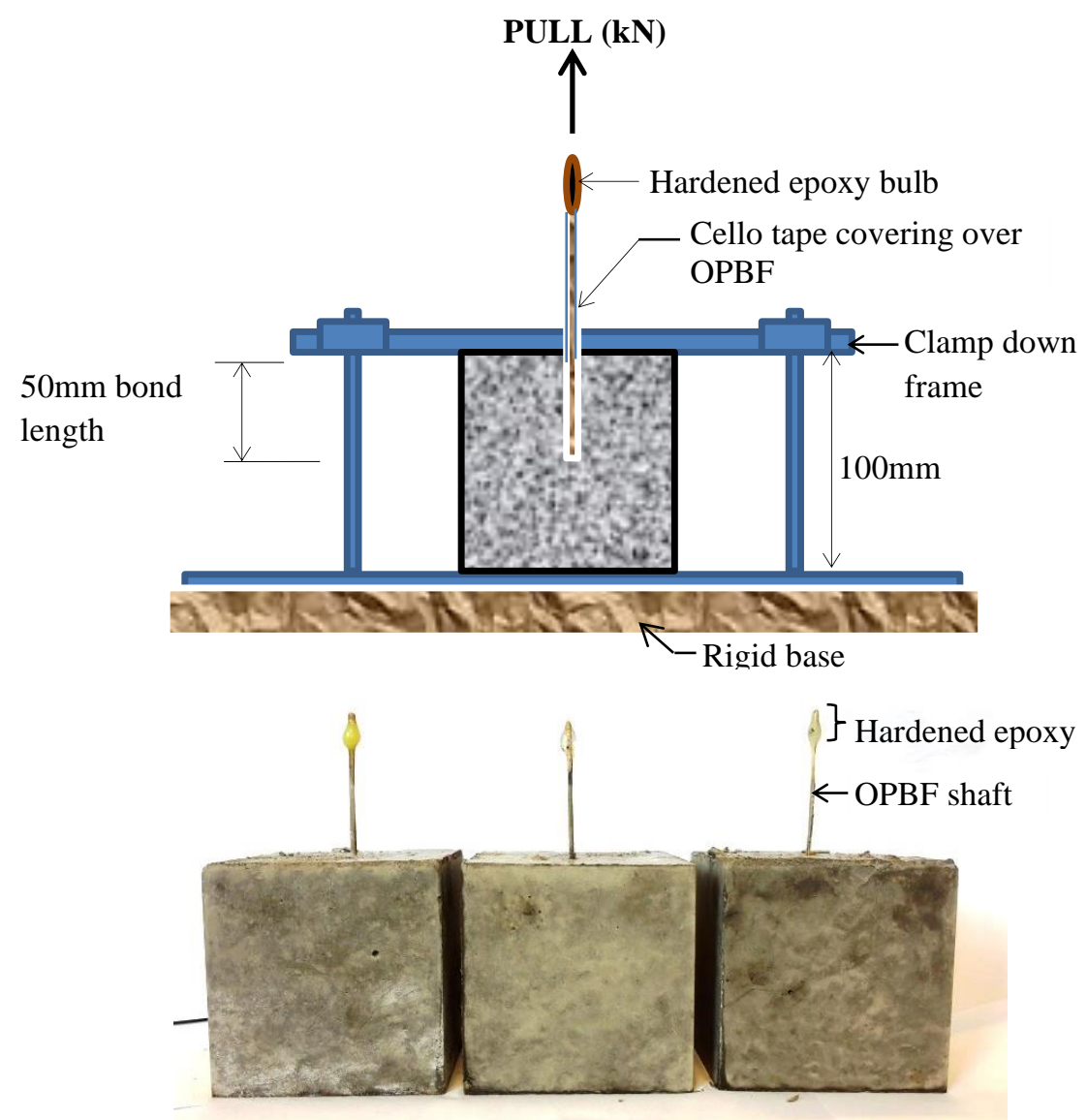

Fig 2.5: (a) Test set up (b) 100x100x 100mm concrete samples with embedded OPBF for pull-out (bond) test 

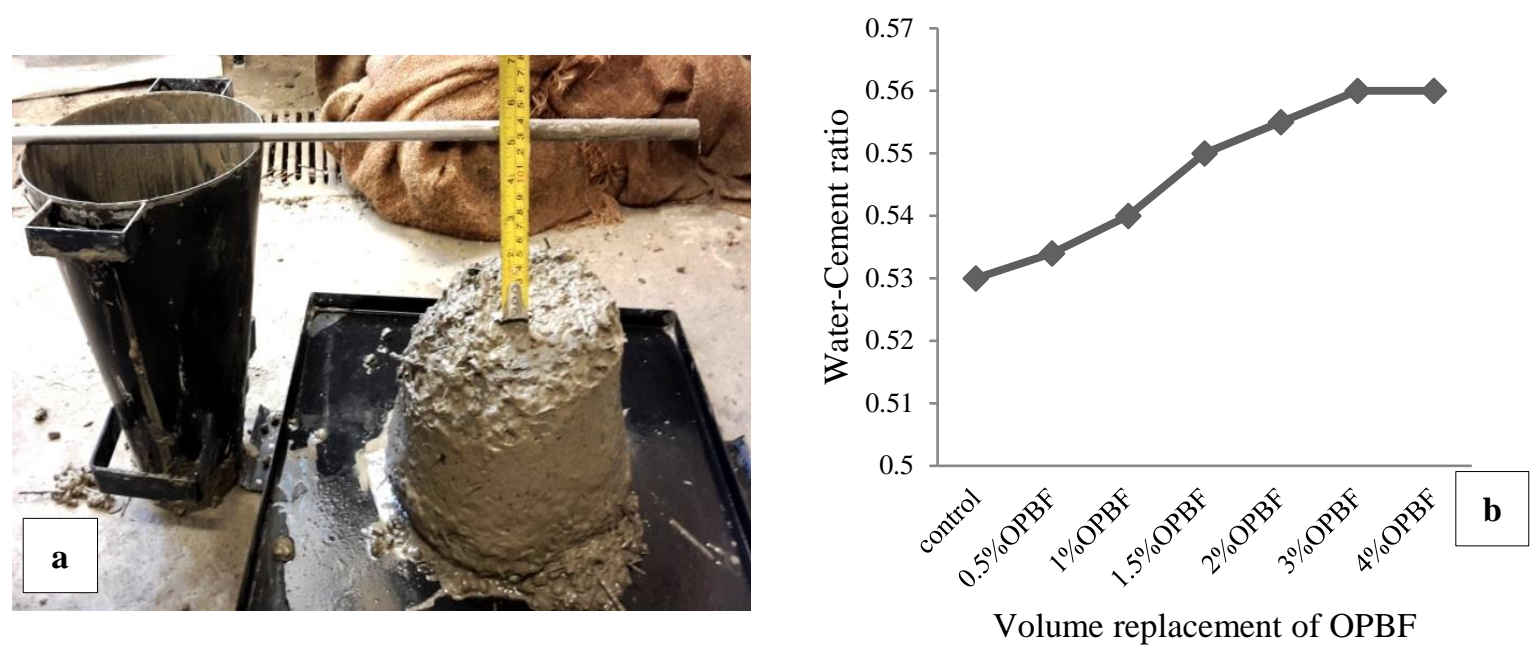

Fig 2.6: (a) Determination of workability through slump test (b) Graph of water-cement ratio

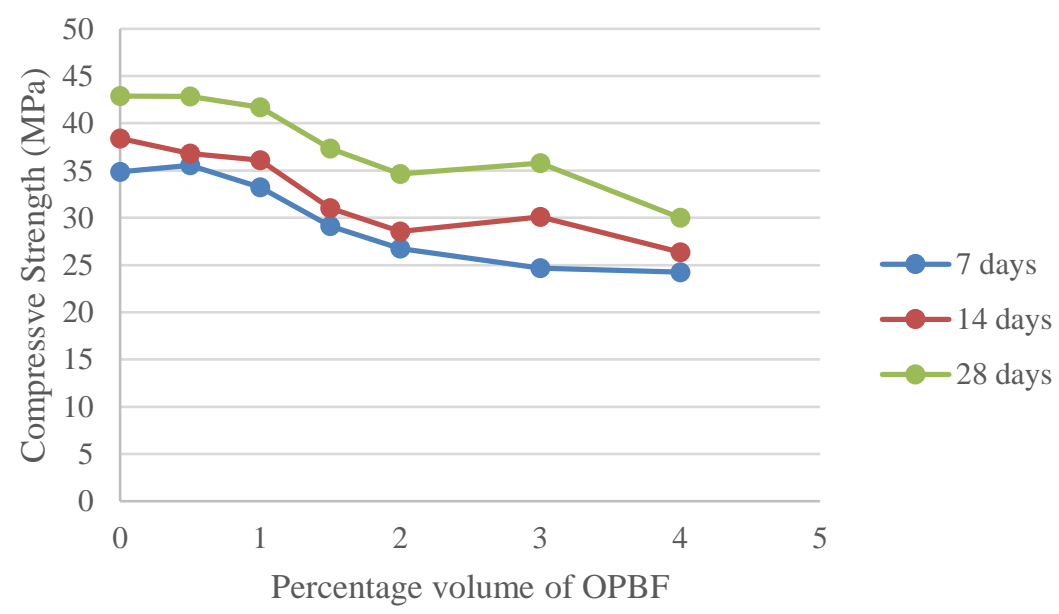

Fig 2.7: Compressive strength of $100 \times 100 \times 100 \mathrm{~mm}$ samples at 7,14 and 28 days

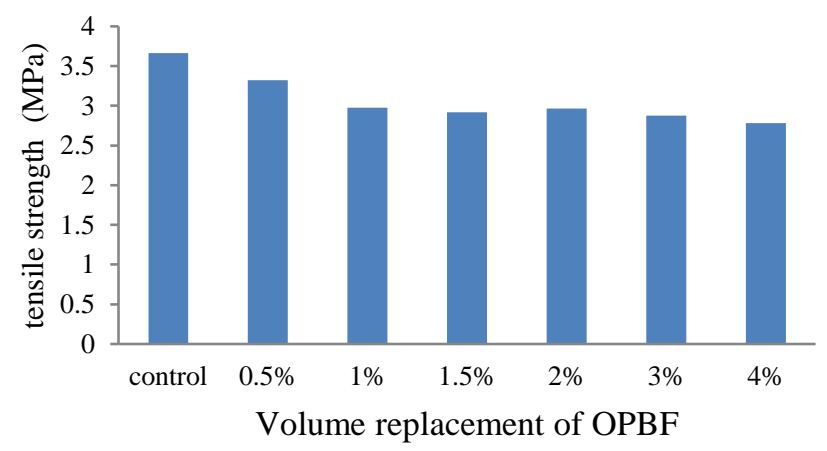

Fig 2.8: 28-days splitting tensile test of 100x200mm cylindrical samples 


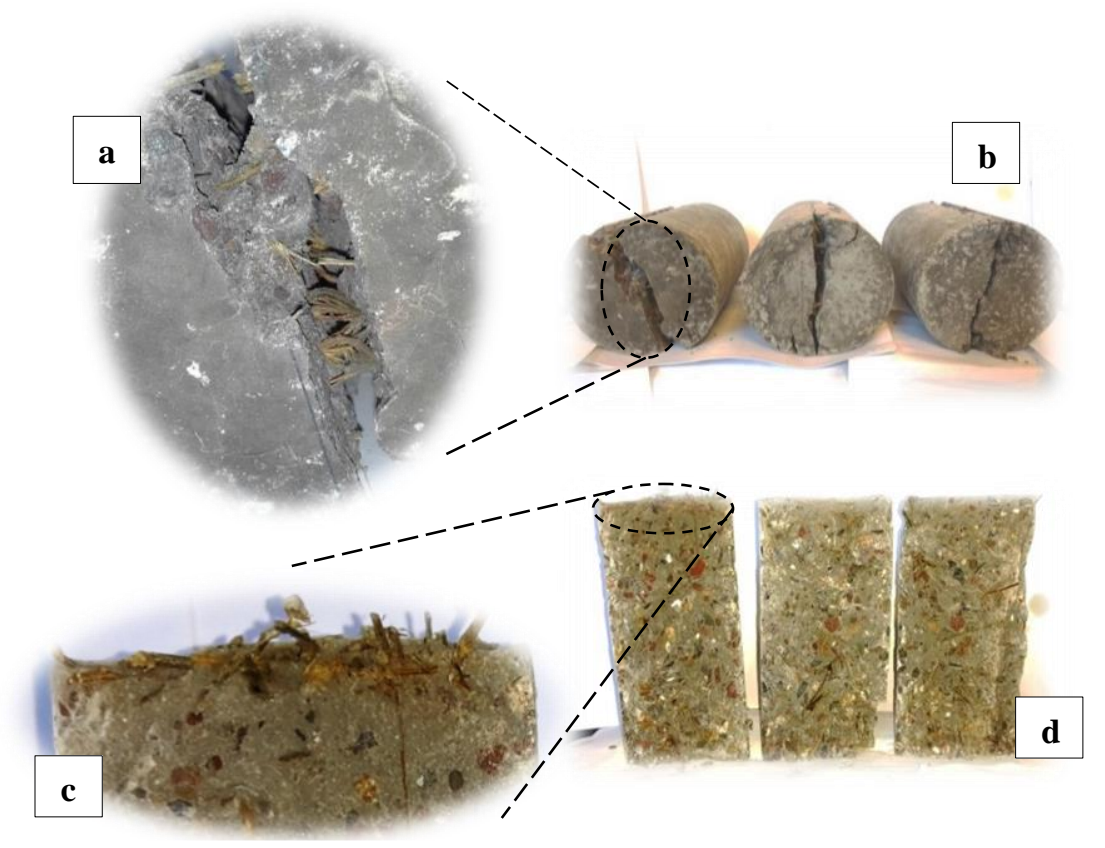

Fig 2.9: Failed specimen details (a) Bridging of failure plane by OPBF (b) Split 100x200mm cylindrical OPBFconcrete samples (c) Agglomeration of OPBF at top of concrete sample (d) Split-halves of 100x200mm OPBF concrete cylindrical specimen

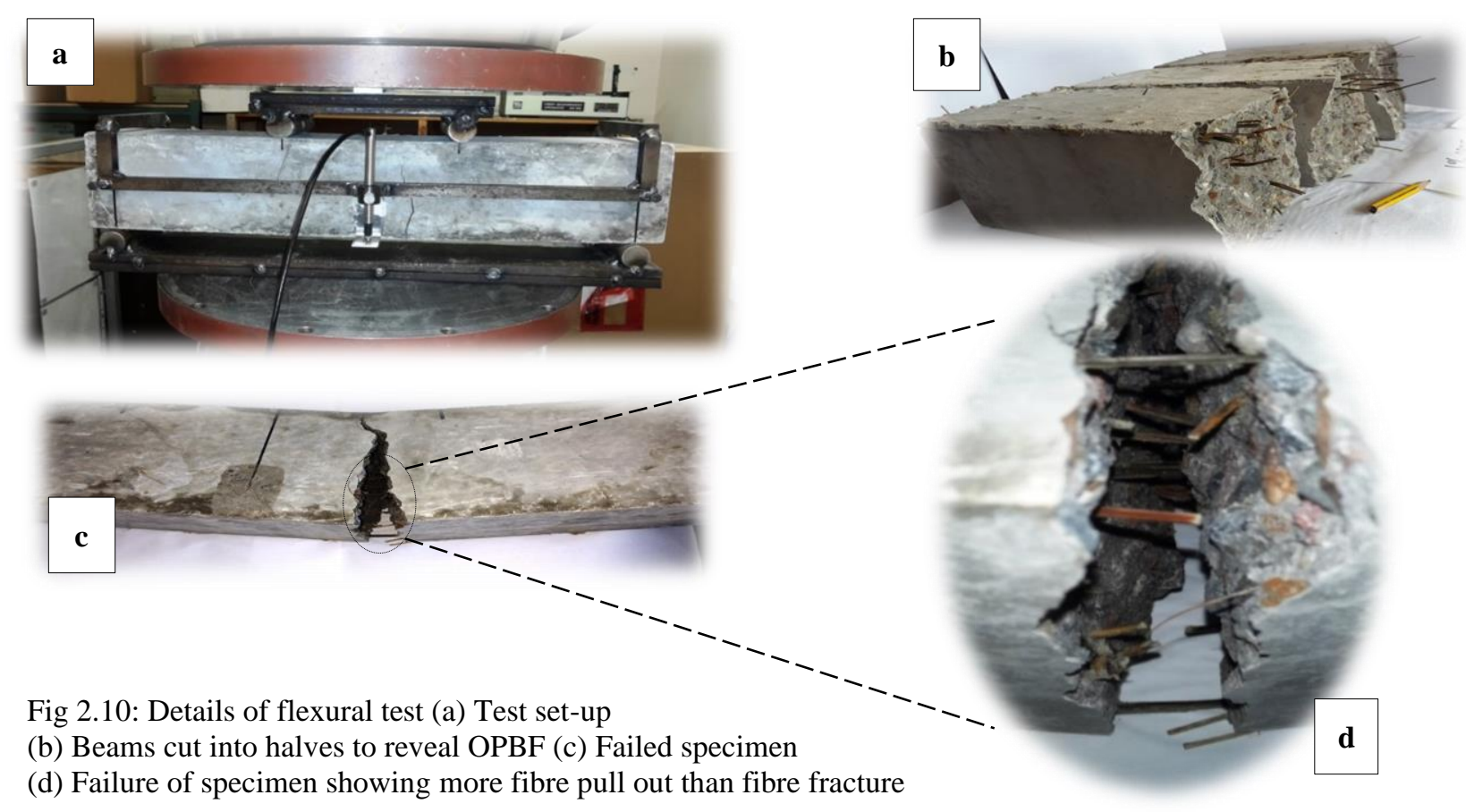




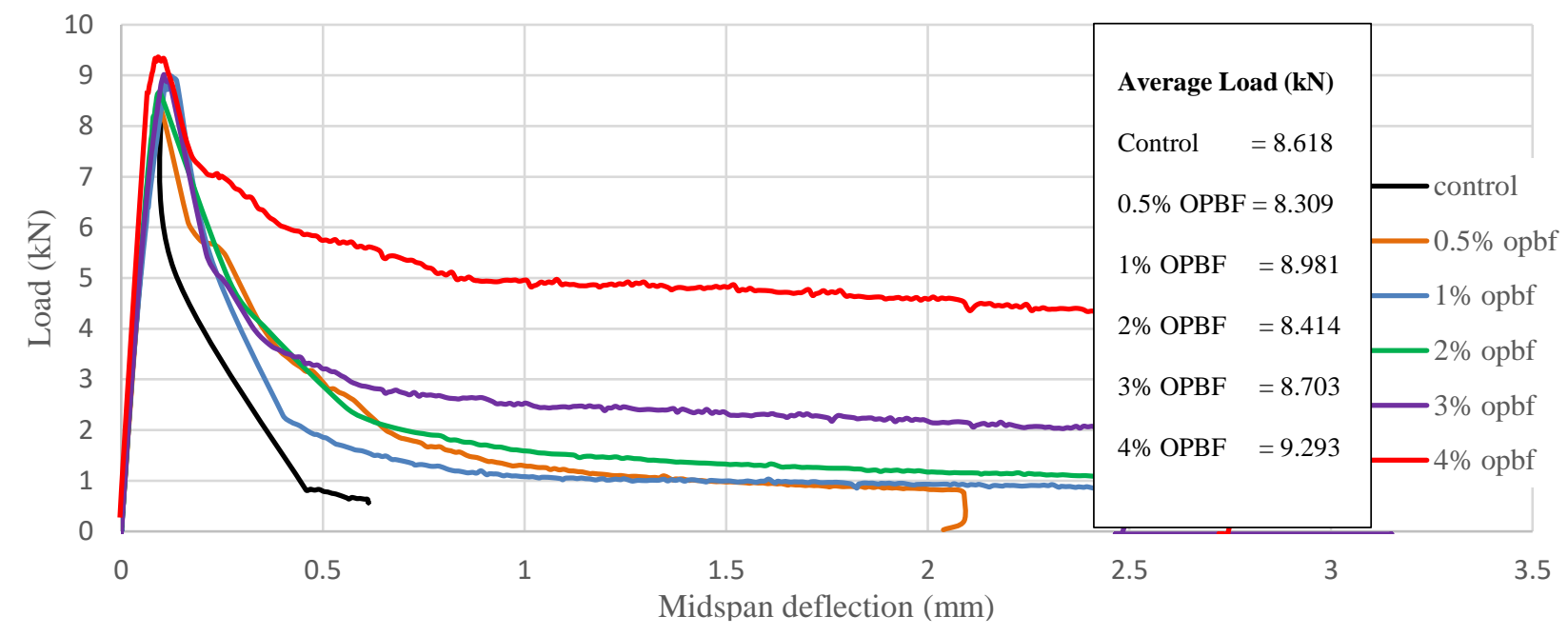

Fig 2.11: 28 days flexural loading curves of 100x100x500mm concrete beams

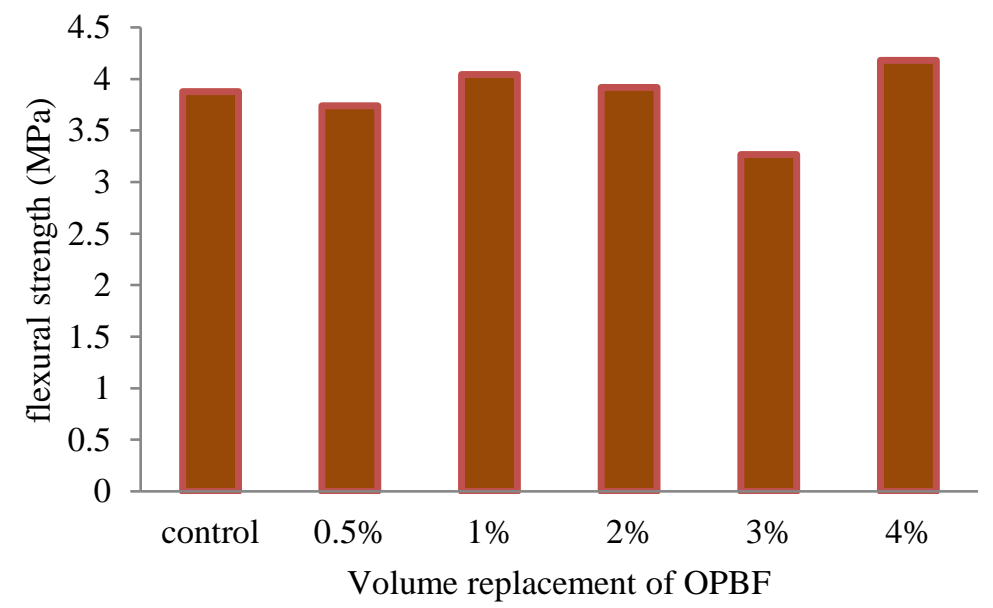

Fig 2.12: Maximum yield strength results on 100x100x500mm 


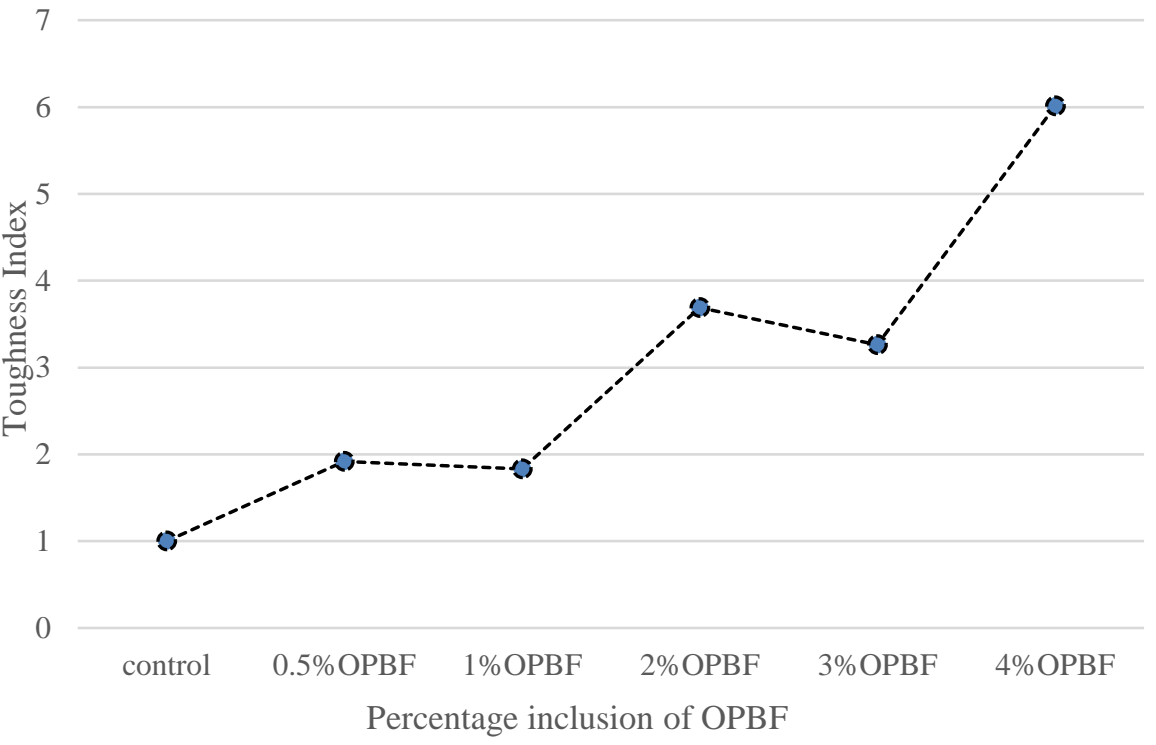

Fig 2.13 Flexural Toughness Index at 28 days

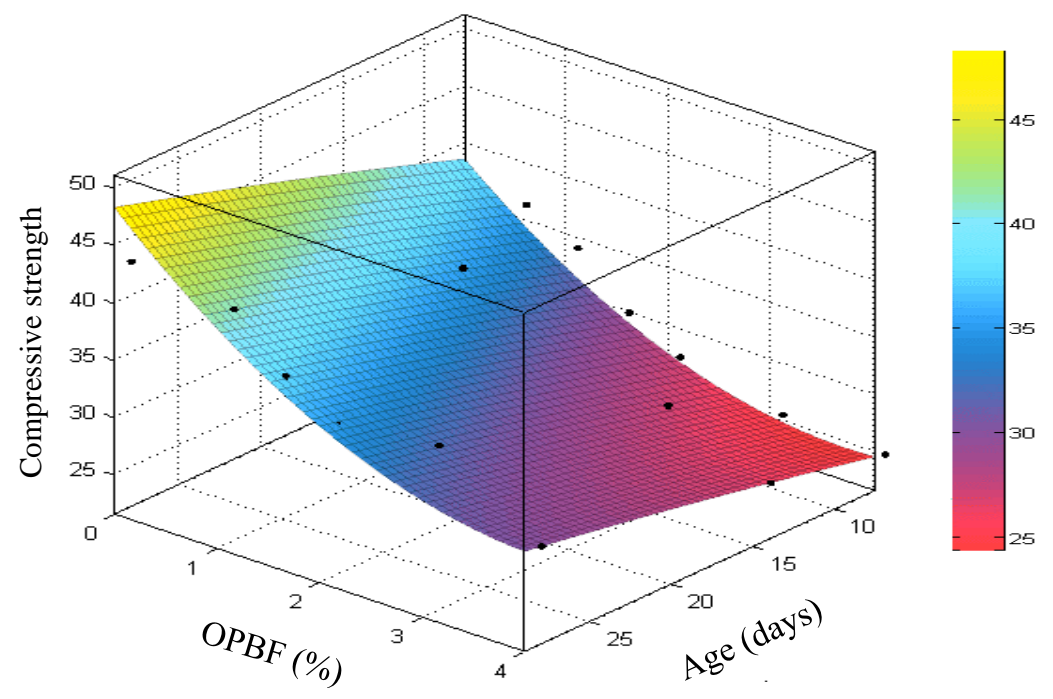

Fig 3.1 Response surface plot of compressive strength $v s$ OPBF content $v s$ age of samples 